\title{
Study Reference Publication Identifier
}

National Cancer Institute

\section{Source}

National Cancer Institute. Study Reference Publication Identifier. NCI Thesaurus. Code C94132.

A unique symbol that establishes identity of a publication related to the study protocol background. 